\title{
Tail of the Epididymis
}

National Cancer Institute

\section{Source}

National Cancer Institute. Tail of the Epididymis. NCI Thesaurus. Code C33732.

The lower part of the epididymis. 